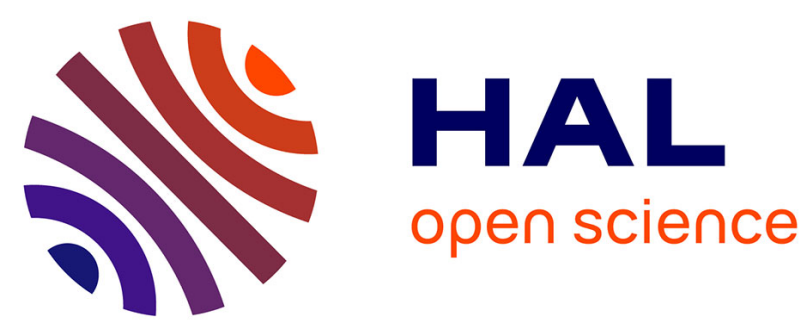

\title{
Letter: A Retrospective Cohort Study of Longitudinal Audiologic Assessment in Single and Fractionated Stereotactic Radiosurgery for Vestibular Schwannoma
}

Constantin Tuleasca, Jean Regis, Marc Levivier

\section{- To cite this version:}

Constantin Tuleasca, Jean Regis, Marc Levivier. Letter: A Retrospective Cohort Study of Longitudinal Audiologic Assessment in Single and Fractionated Stereotactic Radiosurgery for Vestibular Schwannoma. Neurosurgery, inPress, 10.1093/neuros/nyz371 . hal-02290037

\section{HAL Id: hal-02290037 \\ https://hal.sorbonne-universite.fr/hal-02290037}

Submitted on 17 Sep 2019

HAL is a multi-disciplinary open access archive for the deposit and dissemination of scientific research documents, whether they are published or not. The documents may come from teaching and research institutions in France or abroad, or from public or private research centers.
L'archive ouverte pluridisciplinaire HAL, est destinée au dépôt et à la diffusion de documents scientifiques de niveau recherche, publiés ou non, émanant des établissements d'enseignement et de recherche français ou étrangers, des laboratoires publics ou privés. 


\title{
Letter: A retrospective cohort study of longitudinal audiologic assessment in single and fractionated stereotactic radiosurgery for vestibular schwannoma
}

\author{
Constantin Tuleasca ${ }^{1,2,3,4,5,6}$, MD-PhD, Jean Régis, MD, Marc Levivier ${ }^{1,2}$, MD, PhD \\ ${ }^{1}$ Department of Clinical Neurosciences, Neurosurgery Service and Gamma Knife Center, Lausanne \\ University Hospital (CHUV), ${ }^{2}$ University of Lausanne (Unil), Faculty of Biology and Medicine \\ (FBM), ${ }^{3}$ Signal Processing Laboratory (LTS 5), Ecole Polytechnique Fédérale de Lausanne (EPFL), \\ ${ }^{4}$ Sorbonne Université, Faculté de Médecine, ${ }^{5}$ Assistance Publique-Hôpitaux de Paris, Hôpitaux \\ Universitaires Paris-Sud, Centre Hospitalier Universitaire Bicêtre, Service de Neurochirurgie, Paris, \\ France; ${ }^{6}$ Sorbonne Université, Faculté de Médecine; ${ }^{7}$ Stereotactic and Functional Neurosurgery Service \\ and Gamma Knife Unit, Assistance-Publique, Hôpitaux de Marseille, CHU Timone, Marseille, France
}

Corresponding author: Constantin Tuleasca, MD-PhD, Assistance Publique-Hôpitaux de Paris, Hôpitaux Universitaires Paris-Sud, Centre Hospitalier Universitaire Bicêtre, Service de Neurochirurgie, Paris, France; Sorbonne Université, Faculté de Médecine; Centre Hospitalier Universitaire Vaudois, Neurosurgery Service and Gamma Knife Center, Rue du Bugnon 4446, BH-08, CH-1011, Lausanne, Switzerland;

Tel: +41-21-314-26-02; Fax: +41-21-314-11-99; e-mail: constantin.tuleasca@gmail.com

\section{Funding:}

Constantin Tuleasca gratefully acknowledges receipt of a 'Young Researcher in Clinical Research Grant' (Jeune Chercheur en Recherche Clinique) from the University of Lausanne (UNIL), Faculty of Biology and Medicine (FBM) and the Lausanne University Hospital (CHUV).

\section{Conflict of interest:}

None. 


\section{Dear Editor,}

We have read with great interest the recent article by Khattab et al., related to hearing preservation in patients with vestibular schwannomas (VSs) undergoing single fraction versus hypofractionnated radiosurgery (RS, by Novalis, TX Linear Accelerator, Varian Medical Systems, Palo Alto, California) ${ }^{1}$. This retrospective analysis apparently supports the use of fractionated RS to preserve hearing. However, the reader must be aware of several potential bias of the present paper, which are endangering the external validity.

Firstly, this is not a randomized controlled trial, but a retrospective review of data. Moreover, the sample size is extremely small in two of the three selected groups, mainly in the ones corresponding to single and three fractions. In this sense, the conclusion of the paper should be cautiously interpreted.

Secondly, different target volumes (TV) were treated for $1(n=12), 3(n=12)$ or 5 $(n=32)$ fractions, with a median of $0.745 \mathrm{cc}, 1.42 \mathrm{cc}$ and $2.13 \mathrm{cc}$. One has to acknowledge that all these presented volumes are compatible with single fraction RS by other devices, such as the Gamma Knife (GK, Elekta Instruments, AB, Sweden), for example, without any major technical difficulties. This is particularly important due to the relationship with critical surrounding structures, such as the cochlea and the brainstem, as it is now well acknowledged that the SRS dose follow-off in VSs is not the same for Novalis or for $\mathrm{GK}^{2}$.

A third comment is that the single fraction group received a mean dose to the cochlea, which was 10.49 Gy (range 6.75-10.99). This dose is undesirable higher in patients with serviceable hearing before $\mathrm{SRS}^{3}$. In the same sense, what would be the equivalent of the single fraction maximal cochlear dose corresponding to the 3 and 5 fraction cases, if we would have considered 5 Gy as the upper limit for one fraction? It is now well acknowledged that while treating VSs with serviceable hearing with SRS, the maximal dose received by the cochlea should be kept below $5 \mathrm{~Gy}$, so as to give maximal chances to preserve hearing on short and long-term basis ${ }^{4-7}$. In this sense, hearing loss is not really astonishing in the single fraction group. Furthermore, smaller intracanalicular tumors have somewhat more challenging dosimetries, due to the small distance (if such exist) with regards to the cochlea. Khattab et al. ${ }^{1}$ acknowledge the importance of the cochlear dose in the introduction. However, the maximal cochlear dose is not reported, as one would usually do, but the mean dose. Another point which might be questionable is the reported cochlear $0.035 \mathrm{cc}$ point max, which is we suppose arbitrary chosen. It is unclear how the $0.035 \mathrm{cc}$ point max of the cochlea has been established and on what grounds, and how this has or not an impact on hearing preservation. 
Fourthly, it is stated that speech awarness threshold (SAT) did not correlate with the reported mean dose received by the cochlea. Speech Detection Threshold (SDT)/Speech Awareness Threshold (SAT) is the minimum hearing level for speech at which an individual can just detect the presence of speech material $50 \%$ of the time. The listener does not have to identify the material as speech, but must indicate awareness of the presence of speech sounds. The material used to obtain a speech detection threshold should be noted in recording and reporting the results. In this sense, it is not necessarily associated with serviceable hearing, as one would consider the Gardner-Robertson (GR) class $^{8}$ I and II, as classically and standardly described. In fact, the reported outcome might be even considered as extremely subjective. The GR class is usually reported as an objective measure in most of the published single fraction SRS by GK data on hearing preservation for vestibular schwannoma ${ }^{8}$. This allows for an objective and clear compatrison of pre- and post-therapeutic outcomes, at the same followup periods. The GR class contains the pure tonal average (PTA), as a mean of 4 different frequencies, allowing to both evaluate the low and high frequency potential loss. No mention on this objective scale is made by the present paper.

A fifth comment is related to whether the authors applied cochlear sparing in their dosimetry. If the answer is yes, has this being performed for all cases described in this paper? In the same sense, it is stated that a clinician blinded from the treatment has countoured the cochlea. Was this performed before, or after SRS? Protecting the cochlea and sparing it from higher radiation doses has been a constant preocupation in the single fraction SRS community, especially in the GK users one, during at least the past 10-15 years.

A sixth comment and extremly important as major source of bias, is that the authors state that "due to significant variability in follow-up time and the relatively stable audiologic assesement at late time-point, audiologic outcomes at the last time of follow-up were compared". In other words, they state that the mean radiological follow-up was 2 years (range 0.5, 9.45 years). Did the authors compared a 6 months, 2 years and 9 years audiological follow-up between these groups or even inside the same group? And would this make sense especially in a cohort which received multiple regimen of fractionations, including single fraction?

Lastly, factors associated with serviceable hearing at baseline are, beside those previously evoked: GR class $\mathrm{I}^{9}$, a speech discrimination score $(\mathrm{SDS})>$ or $=80 \%$, a pure tone average $(\mathrm{PTA})<20 \mathrm{~dB}$, a patient age $<60$ years ${ }^{10}$ or SRS within 2 years after diagnosis of VS in normal hearing patients ${ }^{11}$. How were the three groups presented by Khattab et al. ${ }^{1}$ relating to these type of preoperative measurements? 
In the light of the previous, one would have to reflect of the main purpose of the paper by Khattab et al. ${ }^{1}$ in terms of its main message. While being a pure retrospective review, lacking of randomization, would this paper consider patients with serviceable hearing as reported by the standard GR class (and with high level of hearing) or simply patients who subjectively detect the presence of speech material during $50 \%$ of the time? After at least 10 years of SRS cochlear sparing, is this a parameter really taken into account by the present study while considering only the mean dose to the cochlea and delivering an extremely high dose to the single fraction group? Subjective audiologist assessments are being compared at different time-points, and this might also reflect hearing loss due to aging etc? Should we believe that fractionation is the ultimate tool for hearing preservation after this analysis, which has a low statistical power and raises an important number of questions, which put in danger its external validity? The authors state only partially their own bias... 


\section{References:}

1. Khattab MH, Sherry AD, Whitaker R, et al. A Retrospective Cohort Study of Longitudinal Audiologic Assessment in Single and Fractionated Stereotactic Radiosurgery for Vestibular Schwannoma. Neurosurgery. 2019.

2. Gevaert T, Levivier M, Lacornerie T, et al. Dosimetric comparison of different treatment modalities for stereotactic radiosurgery of arteriovenous malformations and acoustic neuromas. Radiotherapy and oncology: journal of the European Society for Therapeutic Radiology and Oncology. 2013;106(2):192-197.

3. Tsao MN, Sahgal A, Xu W, et al. Stereotactic radiosurgery for vestibular schwannoma: International Stereotactic Radiosurgery Society (ISRS) Practice Guideline. Journal of radiosurgery and SBRT. 2017;5(1):5-24.

4. Kondziolka D, Lunsford LD, McLaughlin MR, Flickinger JC. Long-term outcomes after radiosurgery for acoustic neuromas. The New England journal of medicine. 1998;339(20):1426-1433.

5. Kondziolka D, Mousavi SH, Kano H, Flickinger JC, Lunsford LD. The newly diagnosed vestibular schwannoma: radiosurgery, resection, or observation? Neurosurgical focus. 2012;33(3):E8.

6. Tamura $\mathrm{M}$, Carron $\mathrm{R}$, Yomo $\mathrm{S}$, et al. Hearing preservation after gamma knife radiosurgery for vestibular schwannomas presenting with high-level hearing. Neurosurgery. 2009;64(2):289-296; discussion 296.

7. Tuleasca C, George M, Faouzi M, et al. Acute clinical adverse radiation effects after Gamma Knife surgery for vestibular schwannomas. Journal of neurosurgery. 2016;125(Suppl 1):73-82.

8. Gardner G, Robertson JH. Hearing preservation in unilateral acoustic neuroma surgery. The Annals of otology, rhinology, and laryngology. 1988;97(1):55-66.

9. Hasegawa T, Kida Y, Kato T, lizuka H, Yamamoto T. Factors associated with hearing preservation after Gamma Knife surgery for vestibular schwannomas in patients who retain serviceable hearing. Journal of neurosurgery. 2011;115(6):1078-1086.

10. Kano H, Kondziolka D, Khan A, Flickinger JC, Lunsford LD. Predictors of hearing preservation after stereotactic radiosurgery for acoustic neuroma. Journal of neurosurgery. 2009;111(4):863-873.

11. Akpinar B, Mousavi SH, McDowell MM, et al. Early Radiosurgery Improves Hearing Preservation in Vestibular Schwannoma Patients With Normal Hearing at the Time of Diagnosis. International journal of radiation oncology, biology, physics. 2016;95(2):729-734. 